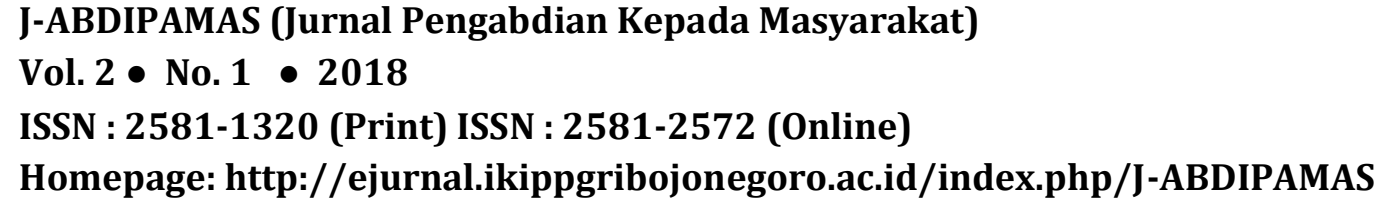

ISSN : 2581-1320 (Print) ISSN : 2581-2572 (Online)

Homepage: http://ejurnal.ikippgribojonegoro.ac.id/index.php/J-ABDIPAMAS

\title{
PELATIHAN PELAPORAN DAN ADMINISTRASI KEPENDUDUKAN BERBASIS MICROSOFT EXCEL PADA FORUM PERANGKAT DESA CIBOLANG
}

\author{
Andi Riyanto ${ }^{1}$, Rina Riniawati ${ }^{2}$, Rusli Nugraha ${ }^{3}$, Eva Marsusanti ${ }^{4}$, \\ Satia Suhada ${ }^{5}$ \\ 1AMIK BSI Sukabumi. Email: andi.iio@bsi.ac.id \\ 2AMIK BSI Sukabumi. Email: rina.rri@bsi.ac.id \\ ${ }^{3}$ AMIK BSI Sukabumi. Email: rusli.rng@bsi.ac.id \\ ${ }^{4}$ AMIK BSI Sukabumi. Email: eva.emr@bsi.ac.id \\ 5STMIK Nusa Mandiri Jakarta. Email: satia.shq@nusamandiri.ac.id
}

\begin{abstract}
Utilization of current technology in supporting work activities is an inevitable requirement, including by the village apparatus. The village as the spearhead of the current development in Indonesia and the village apparatus as the main operator in serving the community in terms of administration will inevitably have to be able to master the technology. By providing training and reporting of population administration to Forum of Village Device Cibolang Sukabumi expected they can use Excel as an effective tool in supporting their administrative activities so that in providing services to the community can run well. Implementation of this PKM activity was held on October 27, 2016 until October 28, 2016 and housed in the auditorium of Cibolang Village Office. PKM activity is also received a very high appreciation from the Village Cibolang device.
\end{abstract}

Keywords: Training reporting and population administration, Microsoft Excel

\begin{abstract}
ABSTRAK
Pemanfaatan teknologi saat ini dalam menunjang aktifitas dalam bekerja merupakan suatu kebutuhan yang tidak dapat dielakkan, termasuk oleh perangkat desa. Desa sebagai ujung tombak pembangunan di Indonesia saat ini dan perangkat desa sebagai operator utama dalam melayani masyarakat dalam hal administrasi mau tidak mau harus mampu menguasai teknologi. Dengan memberikan pelatihan dan pelaporan administrasi kependudukan kepada Forum Perangkat Desa Cibolang Kabupaten Sukabumi diharapkan mereka mampu memanfaatkan Excel sebagai alat bantu yang efektif dalam menunjang kegiatan administrasi mereka sehingga dalam memberikan pelayanan kepada masyarakat dapat berjalan dengan baik. Pelaksanaan kegiatan PKM ini diselenggarakan pada tanggal 27 Oktober 2016 sampai dengan 28 Oktober 2016 dan bertempat di aula Kantor Desa Cibolang. Kegiatan PKM ini juga mendapat apresiasi yang sangat tinggi dari perangkat Desa Cibolang.
\end{abstract}

Kata Kunci: Pelatihan pelaporan dan administrasi kependudukan, Microsoft Excel

\section{PENDAHULUAN}

Saat ini desa merupakan pusat kegiatan dalam penyelenggaran pembangunan di Indonesia. Upaya untuk mengembangkan kemandirian dan kesejahteraan masyarakat desa dapat dilakukan dengan meningkatkan pengetahuan, sikap, keterampilan, perilaku, kemampuan, kesadaran, serta memanfaatkan sumber daya melalui penetapan kebijakan, program, kegiatan, dan pendampingan yang sesuai dengan esensi masalah dan prioritas kebutuhan masyarakat desa (UU No. 6, 2014). Selain itu, desa diharapkan tidak hanya 
mampu menggerakkan masyarakat untuk berpartisipasi dalam pembangunan, tetapi juga mampu menyelenggarakan pelayanan administrasi desa dengan baik (Riyanto, Suherman, \& Prayudi, 2016).

Terdapat 73.707 desa di seluruh Indonesia (Badan Pusat Statistik, 2015). Dengan jumlah desa yang begitu banyak, serta tidak di dukung oleh perangkat desa yang mempunyai kecakapan, profesionalitas dan tata kelola administrasi yang baik, menyebabkan pelayanan terhadap masyarakat tidak akan maksimal. Untuk itu diperlukan kesiapan Sumber Daya Manusia (SDM) yang mempunyai kecakapan, kemampuan dan pengetahuan dalam teknologi informasi.

Tabel 1. Jumlah Populasi Desa

Menurut Klasifikasi Desa

\begin{tabular}{cc}
\hline \hline Klasifikasi Desa & Populasi \\
\hline Desa Perkotaan/Urban & 8.794 \\
\hline Desa Perdesaan/Rural & 64.913 \\
\hline Jumlah & $\mathbf{7 3 . 7 0 7}$ \\
\hline Sumber: (Badan Pusat Statistik, 2015$)$
\end{tabular}

Sumber: (Badan Pusat Statistik, 2015)

Desa Cibolang termasuk salah satu desa yang ada di Kecamatan Gunung Guruh Kabupaten Sukabumi yang memiliki luas wilayah $\pm 122.750 \mathrm{M}^{2}$ dengan jumlah penduduk \pm 6.251 jiwa dan dibagi dalam 3 (tiga) kedusunan, masing-masing terdiri dari : 1) Dusun Legoknyenang; 2) Dusun Pabuaran; dan 3) Dusun Cipicung (Pemerintah Kabupaten Sukabumi, 2007).

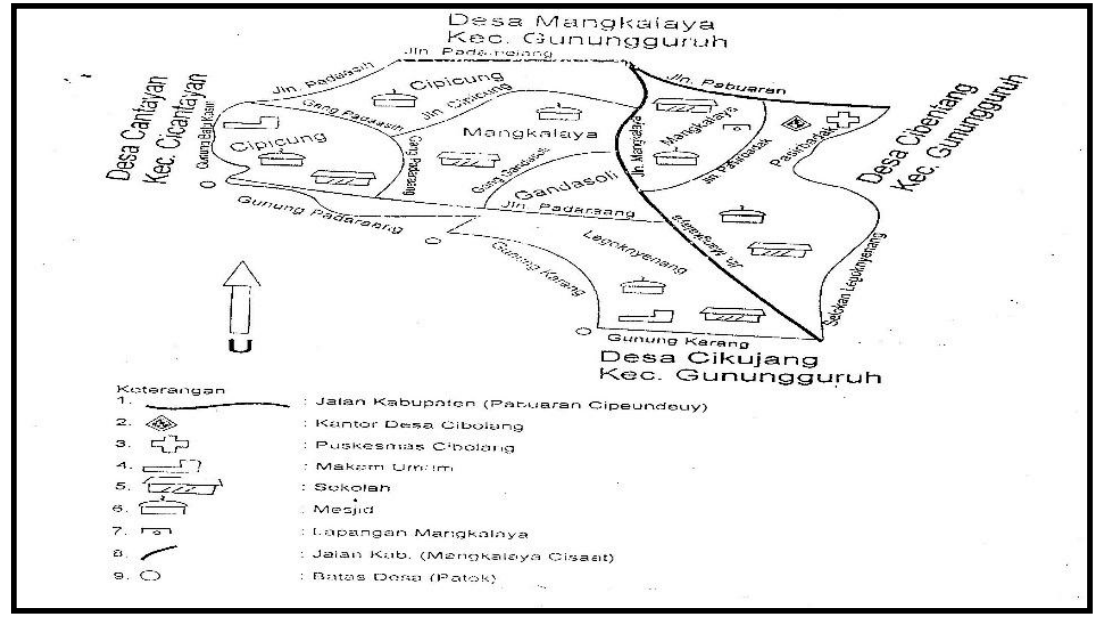

Sumber : (Pemerintah Kabupaten Sukabumi, 2007)

Gambar 1. Peta Desa Cibolang, Kecamatan Gunungguruh, Kabupaten Sukabumi

Dengan luas wilayah dan jumlah penduduk yang sangat besar tersebut, dibutuhkan perangkat desa yang sigap dan memiliki kemampuan dan pengetahuan di bidang teknologi untuk memudahkan dalam memberikan pelayanan terhadap masyarakat.

Untuk itulah pelaksanaan pengabdian pada masyarakat berupa pelatihan pelaporan dan administrasi kependudukan berbasis Microsoft Excel diberikan kepada forum perangkat Desa Cibolang agar mereka mempunyai kemampuan dan keahlian dalam mengolah data administrasi kependudukan dan mampu melayani masyarakat Desa Cibolang dengan baik. 


\section{METODE PELAKSANAAN}

Pelaksanaan di bagi dalam 3 (tiga) program dan dilaksanakan selama 2 (dua) hari. Hari pertama adalah melaksanakan program pertama berupa pengenalan Microsoft Excel, dengan materi pengenalan jendela Microsoft Excel dan mengolah lembar kerja dalam Excel dengan tujuan agar perangkat Desa Cibolang mempunyai kemampuan membuat dokumen administrasi beserta pelaporan kependudukan dan juga untuk memudahkan mereka mengolah data administrasi kependudukan tersebut dengan benar. Dalam mengolah lembar kerja Excel, materi yang diberikan berupa menyisipkan dan menambah lembar kerja baru, merubah nama lembar kerja, menyisipkan baris atau kolom, merubah lebar kolom atau baris, menghapus kolom atau baris, membuat catatan (komentar) pada sel dan memberi sel pembanding.

Program kedua yang dilaksanakan pada hari ke-2 (dua) dengan materi berupa pengenalan rumus dan fungsi dalam Excel yang terdiri dari rumus dan fungsi dasar, fungsi matematika, fungsi string, fungsi logika, dan fungsi tabel. Kemudian materi berikutnya adalah membuat grafik sederhana yang terdiri dari materi berupa mengolah chat wizard (grafik) dan memodifikasi grafik. Maksud diberikannya materi rumus dan fungsi serta grafik adalah agar perangkat Desa Cibolang mempunyai kemampuan tidak hanya sebatas membuat dokumen administrasi saja, selain itu mampu memaksimalkan Excel dalam membuat laporan pertanggungjawaban keuangan desa dan menggambarkannya dalam bentuk grafik.

Program ketiga pada hari ke-2 (dua) adalah berupa latihan kasus. Materi terakhir ini diberikan dengan maksud untuk mengetahui tingkat pemahaman peserta dan juga sebagai bahan evaluasi peserta terhadap materi yang telah diberikan selama 2 (dua) hari.

\section{HASIL DAN PEMBAHASAN}

Kegiatan pengabdian pada masyarakat selama 2 (hari) dapat digambarkan dalam tabel berikut ini :

Tabel 2. Materi, Kegiatan dan Capaian Pelatihan Pelaporan dan Administrasi Kependudukan Berbasis Microsoft Excel

\begin{tabular}{|c|c|c|c|}
\hline Program & Materi & Kegiatan & Capaian \\
\hline 1 & $\begin{array}{l}\text { Pengenalan jendela Excel } \\
\text { dan mengolah lembar kerja } \\
\text { Excel }\end{array}$ & $\begin{array}{l}\text { - Menyisipkan/menambah lembar } \\
\text { kerja baru } \\
\text { - Memberi/mengganti nama sheet } \\
\text { - Menyisipkan baris/kolom } \\
\text { - Mengubah lebar kolom/baris } \\
\text { - Menghapus kolom/baris } \\
\text { - Membuat catatan pada sel }\end{array}$ & $\begin{array}{l}\text { Diharapkan peserta } \\
\text { mempunyai } \\
\text { kemampuan membuat } \\
\text { dokumen administrasi } \\
\text { dan pelaporan } \\
\text { kependudukan }\end{array}$ \\
\hline 2 & $\begin{array}{l}\text { Pengenalan rumus, fungsi } \\
\text { dan grafik }\end{array}$ & $\begin{array}{l}\text { - } \text { Bekerja dengan rumus dan fungsi } \\
\text { matematika } \\
\text { - } \text { Menerapkan fungsi statistik } \\
\text { - } \text { Menerapkan fungsi string } \\
\text { - } \text { Menerapkan fungsi logika } \\
\text { - Menerapkan fungsi tabel } \\
\text { - Mengolah dan memodifikasi } \\
\text { grafik }\end{array}$ & $\begin{array}{l}\text { Diharapkan peserta } \\
\text { mampu menggunakan } \\
\text { berbagai rumus dan } \\
\text { fungsi serta grafik } \\
\text { dalam membuat laporan } \\
\text { administrasi dan } \\
\text { pertanggungjawaban } \\
\text { keuangan desa. }\end{array}$ \\
\hline
\end{tabular}




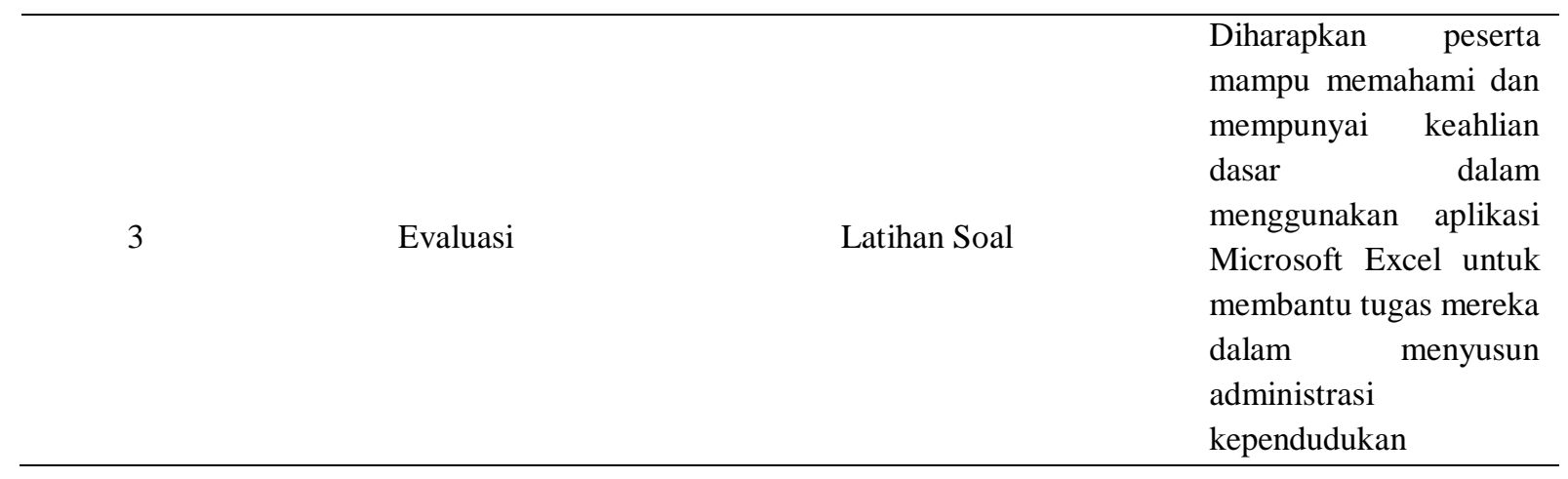

1. Program pertama pada hari pertama adalah pengenalan jendela Microsoft Excel dan mengolah lembar kerja Excel.

2. Program kedua pada hari kedua dan sesi 1 dengan materi pengenalan rumus, fungsi dan grafik

3. Sedangkan sesi 2 pada hari kedua berupa evaluasi dengan memberikan latihan soal studi kasus.

\section{SIMPULAN}

Kegiatan pengabdian pada masyarakat pada forum perangkat Desa Cibolang yang mengambil tema pelatihan pelaporan dan administrasi kependudukan berbasis Microsoft Excel ini sangat berdaya guna untuk menunjang perangkat desa tersebut dalam membuat laporan administrasi kependudukan dan laporan lainnya sebagai bentuk pelayanan kepada masyarakat agar lebih efektif dan efisien sehingga roda pemerintahan desa dapat berjalan dengan baik.

\section{DAFTAR RUJUKAN}

Badan Pusat Statistik. (2015). Statistik Keuangan Pemerintah Desa. Jakarta.

Pemerintah Kabupaten Sukabumi. Peraturan Daerah Kabupaten Sukabumi Tentang Pemekaran Desa Cibolang Dan Desa Mangkalaya Kecamatan Gunungguruh, Pub. L. No. 10 (2007). Indonesia.

Riyanto, A., Suherman, A., \& Prayudi, D. (2016). Akuntansi Dalam Perspektif Pengelolaan Keuangan Desa. In Seminar Nasional Ilmu Pengetahuan dan Teknologi Komputer (pp. 444-450). Jakarta: PPPM Nusamandiri.

UU No. 6. Undang-Undang Republik Indonesia Nomor 6 Tahun 2014 Tentang Desa, Pub. L. No. 6 (2014). Indonesia. 